\title{
La temporalidad en el empleo público como fallo activo en la administración
}

\author{
Temporality in public employment as an active failure \\ in the Administration
}

\author{
Pedro T. Nevado-Batalla Moreno \\ Universidad de Salamanca (España) \\ ORCID: https://orcid.org/0000-0002-6773-9622 \\ pnevado@usal.es
}

\begin{abstract}
NOTA BIOGRÁFICA
Profesor Titular de Derecho Administrativo. Director del Centro de Investigación para la Gobernanza Global de la USal. Coordinador del Programa de Doctorado Estado de Derecho y Gobernanza Global, responsable de la línea de investigación transparencia, buen gobierno y garantías de la actividad administrativa. Miembro del Comité de Ética Pública de Castilla y León y del Observatorio de la Vida Militar.
\end{abstract}

\section{RESUMEN}

La elevada tasa de empleo temporal en la Administración Pública española se ha convertido en un problema estructural, en un fallo activo, que impide desarrollar una correcta gestión del personal, restando capacidad de eficacia y eficiencia a la organización pública. Los servicios públicos, como pilares del Estado del bienestar, se ven negativamente afectados por la imposibilidad material de desarrollar políticas de personal adecuadas a las necesidades reales de los ciudadanos. Esta situación tiene como principal causa el continuado incumplimiento de las normas reguladoras de la temporalidad, convirtiendo en ordinario, abusivo incluso, el uso de técnicas excepcionales. Los negativos efectos de este incumplimiento se advierten a través de la observación de los colectivos afectados y, en síntesis, del evidente daño al interés general poniendo en riego el modelo constitucional de empleo público, además de restar legitimidad y fortaleza a la propia Democracia. Resolver el problema, más allá de soluciones inmediatas basadas en la consolidación de situaciones de temporalidad y el refuerzo de medidas disuasorias, pasa por una mirada a largo plazo en la que el respeto a la legalidad sea el reflejo de una obligada y elemental lealtad institucional con el Estado democrático y de Derecho.

\section{PALABRAS CLAVE}

Administración pública; empleo público; temporalidad; interinidad; libre acceso; mérito y capacidad; servicio público; planificación.

\begin{abstract}
The high rate of temporary employment in the Spanish Public Administration has become a structural problem, an active failure, which prevents the development of proper personnel management, reducing the effectiveness and efficiency of the public organization. Public services, as pillars of the welfare state, are negatively affected by the material impossibility of developing personnel policies appropriate to the real needs of citizens. The main cause of this situation is the continued non-compliance with the regulations governing temporality, making it ordinary, even abusive, the use of exceptional techniques. The negative effects of this non-compliance are noticed through the observation of the affected groups and, in short, the evident damage to the general interest, putting the constitutional model of public employment at risk, in addition to reducing the legitimacy and strength of Democracy itself.
\end{abstract}


DA. Nueva Época - N. 8, diciembre 2021 - ISSN: 1989-8983 - DOI: https://doi.org/10.24965/da.i8.11027 - [Págs. 115-136]

Resolving the problem, beyond immediate solutions based on the consolidation of temporary situations and the reinforcement of dissuasive measures, goes through a long-term look in which respect for legality is the reflection of an obligatory and elementary institutional loyalty with the democratic State and of Law.

\section{KEYWORDS}

Public administration; public employment; temporality; interim; free access; merit and capacity; public service; planning.

\section{SUMARIO}

1. LAESTABILIDAD EN EL EMPLEO PÚBLICO COMO FORTALEZA DEMOCRÁTICA. 2. LATEMPORALIDAD Y SUS VÍCTIMAS. 2.1. EL PERSONAL TEMPORAL COMO VÍCTIMA Y VICTIMARIO. 2.2. ASPIRANTES A FUNCIONES Y CARGOS PÚBLICOS: EL DIFÍCIL EQUILIBRIO DE LA CONSOLIDACIÓN EXTRAORDINARIA CON LOS PRINCIPIOS DE MÉRITO Y CAPACIDAD, Y LIBRE ACCESO A FUNCIONES Y CARGOS PÚBLICOS. 2.3. EL EMPLEADO PÚBLICO COMO VÍCTIMA. 2.4. LOS CIUDADANOS COMO VÍCTIMAS INDOLENTES. 3. LA TEMPORALIDAD COMO ALTERNATIVA ORGANIZATIVA IMPROPIA. 3.1. EL FACTOR PRESUPUESTARIO COMO CAUSA DE LA TEMPORALIDAD. 3.2. EL CONSENTIMIENTO DE LA MALA ORGANIZACIÓN COMO DETERMINANTE DE LA TEMPORALIDAD. 4. LA DISUASIÓN DE LA TEMPORALIDAD A TRAVÉS DE LA RESPONSABILIDAD: EL ESCALAMIENTO HACIA LA PREVARICACIÓN PENAL. 4.1. LA RESPONSABILIDAD COMO ROMPIENTE DE LA IMPUNIDAD. 4.2. LA EXIGENCIA DE RESPONSABILIDAD DESDE UNA PERSPECTIVA DE BUENA ADMINISTRACIÓN. 4.3. EL ESCALAMIENTO PENAL DE LA RESPONSABILIDAD EN MATERIA DE GESTIÓN DE PERSONAL. REFERENCIAS BIBLIOGRÁFICAS.

\section{LA ESTABILIDAD EN EL EMPLEO PÚBLICO COMO FORTALEZA DEMOCRÁTICA}

Dentro de los vectores que contribuyen de manera fundamental a la consolidación y mejora del sistema democrático y de Derecho hay que identificar la estabilidad y profesionalidad de los empleados públicos.

El empleo público, a través de su profesionalidad y estabilidad, representa una de las principales garantías para la democracia que, en el caso de España, recibe un importante respaldo constitucional a través del bloque formado por los artículos 23,2, 28.1, 103.3 y 149.1.18.

Son los empleados públicos los que van a materializar a través de su desempeño el modelo social y democrático de Derecho con el que se adjetiva el Estado. Es el empleo público, el que posibilita una democracia. real, creíble a través del carácter tangible de unos servicios públicos adecuadamente prestados. Y ello, sin perjuicio de su papel como contrapeso a cualquier intento de exceso o arbitrariedad política y modalidad primaria de participación a través del derecho fundamental de acceso a funciones y cargos públicos previsto en el artículo 23.2 CE.

Por tanto, no es sólo el buen funcionamiento de una organización compleja y la importancia del personal en esa organización como elemental, pueril podría decirse, postulado que debe tener en consideración, cualquier gestor. Que el personal en una organización es un recurso fundamental supone recordar una obviedad, pero no se puede desconocer la dimensión democrática que por sí mismo tiene y representa empleo público.

En este sentido, el Dictamen del Comité Económico y Social Europeo sobre Principios para los servicios públicos que contribuyen a la estabilidad del régimen democrático (2021/C 56/03), al considerar a los servicios públicos como «estabilizadores automáticos» que defienden los valores fundamentales de la democracia, otorga al personal al servicio de la Administración el más alto valor en su contribución a la solidez del sistema democrático.

Desde otro punto de vista, pero abundando en la misma idea, el trabajo desarrollado por el Instituto de Calidad del Gobierno de la Universidad de Gotemburgo a través de distintos estudios e informes demuestra que la confianza en las instituciones y por extensión en el personal a su servicio, facilita la construcción de un modelo de Estado del bienestar con amplios beneficios sociales para los ciudadanos. Jiménez Asensio comentando el Índice sobre Calidad de los Gobiernos subnacionales en los países de la Unión Europea elaborado el citado Instituto, lo expresa con claridad:

«Aunque no cotice políticamente al alza, al menos en nuestro país, nadie mínimamente informado duda de que la calidad institucional es uno de los factores que facilita el desarrollo económico, la cohesión social y la mejora de la vida de la ciudadanía» (Jiménez Asensio, 2021). 
Todo lo expuesto conduce a visualizar la sólida relación que existe entre el empleo público y la fortaleza democrática del estado, entendida tanto desde una dimensión política, como de efectividad en lo tocante a su progreso y desarrollo económico y social. Relación entre empleo público y democracia que tiene su correlato en la estabilidad.

Debe entenderse o más bien recordarse por ser una pared maestra de un modelo democrático de función pública, que la estabilidad sólo puede entenderse desde la consideración de unos empleados públicos definidos, según el cuadro de previsiones constitucionales citado, por su profesionalidad asegurada desde el inicio de su carrera como servidores públicos a través de la igualdad de acceso y la superación de un proceso de concurrencia competitiva capaz de decantar el mejor y mayor mérito al servicio del interés general.

Resulta por tanto un error comparar la estabilidad del empleado público con la caracterización temporal que pueda recibir la contratación en el ámbito privado. La estabilidad no es un factor que privilegia al empleo público de privado por cuanto son realidades laborales incomparables, mucho más si el vínculo del empleado público con la Administración nace del nombramiento como funcionario público.

Las necesidades del Estado social y democrático de Derecho sólo pueden ser atendidas adecuadamente, asegurando respuestas de calidad sostenibles a largo plazo, a través de empleados públicos cuyo desempeño se realiza de manera estable y sólo de manera muy excepcional y minoritaria, por motivos de interés general inaplazable, por empleados en régimen de temporalidad.

Los problemas relativos a la estabilidad en el empleo público tienen, sin duda, como se verá, un arranque organizativo a través de decisiones desacertadas o por abuso de técnicas impropias como las que definen las situaciones de temporalidad. Pero el mayor reto al que se enfrenta la estabilidad del empleado público puede identificarse en la incapacidad para ubicar al empleo público y su modelo de gestión en el eje de la democracia como un elemento fundamental de ésta.

Esta idea, debería capilarizar al conjunto de la ciudadanía que debería ver en cada empleado público un factor de desarrollo social, económico y, sobre todo democrático. Motivo por el que la sociedad (que es el aporte del empleo público cuyo acceso, recordemos, es un derecho fundamental) debería apreciar el significado valor del empleo público y exigir su atención y cuidado. El ciudadano, no debería ver en la normativa sobre empleo público privilegios o desigualdad, sino técnicas para asegurar un desempeño que beneficia al conjunto del sistema constitucional con un directo retorno de beneficios a su situación individual sea la que sea.

Pero este planteamiento no es un dogma. La otra parte de la ecuación debe representarse a través de una ejemplaridad tangible en el desempeño y la gestión de la carrera profesional del empleado público, desde su inicio en la selección hasta la finalización de aquella.

Los fundamentos del empleo público, entre ellos, la estabilidad o permanencia en el cargo, no se sostienen desde la teoría o el mandato normativo. Requieren de una práctica correcta y cumplidora de tal forma que los desaciertos y las inobservancias minan su legitimidad y el convencimiento social como elementos necesarios para garantizar el modelo democrático. Como se podrá comprobar más adelante, la mirada sobre el empleo público define buena parte de la confianza ciudadana en sus instituciones por cuanto a la sociedad, pero también al ciudadano individualmente considerado le cuesta disociar comportamientos por lo que suele tender a una visión global que convierte en una opinión general.

Las decisiones organizativas correctas neutralizan en su origen muchos factores de riesgo de largo efecto en la ciudadanía que es, en definitiva, el fundamento, el cimiento de todo el sistema democrático y su razón de ser.

Todo lo expuesto conduce a evidenciar que las malas políticas y actuaciones en materia de personal no sólo reflejan el daño a la organización dificultando alcanzar sus fines. En el ámbito público supone un comportamiento desleal con el sistema democrático.

La temporalidad en el empleo público no es sólo un problema de organización al dificultar el logro concreto de salvaguardar el bien común a largo plazo. Es una patología con efecto sobre la propia democracia que obliga a decidir y actuar mejor, esa es la clave. Y no es tan difícil, como se podrá comprobar a lo largo del trabajo no hay que inventar nada, solo hay que extender, aplicar, lo que ya se conoce y se encuentra articulado desde hace décadas.

\section{LA TEMPORALIDAD Y SUS VÍCTIMAS}

La desbocada situación de la temporalidad del empleo público ha sido calificada como un problema estructural por el Real Decreto-ley 14/2021, de 6 de julio, de medidas urgentes para la reducción de la temporalidad en el empleo público (fundamento, como se sabe, del correspondiente Proyecto de Ley). 
La temporalidad, cuantificada en una cifra cercana al $30 \%$ de los empleados públicos en España (muy superior a la cifra existente en el ámbito privado ${ }^{1}$ ), muestra bien a las claras que, sin distinción política o territorial, quienes debían haber gestionado los recursos humanos de la correspondiente Administración de acuerdo a parámetros de acierto y corrección han tomado decisiones que, con el tiempo, se han mostrado claramente perjudiciales para el interés general.

Decisiones organizativas que han puesto en verdadero aprieto al propio modelo constitucional de empleo público asentado, entre otros, en el principio de mérito y capacidad. Y más que por actos expresos, por una inacción o molicie en el desempeño de sus funciones (ausencia de convocatorias periódicas y sistemáticas), absolutamente lesiva para la organización pública que, como se acaba de apuntar, ha puesto en riesgo el sistema de mérito y capacidad pero también el de igualdad y no discriminación en el acceso a funciones y cargos públicos, alcanzando de lleno al pilar de legalidad del Estado de Derecho.

Pese a que la falta de memoria político-administrativa es un mal que afecta a la Administración y Gobierno de nuestros días del tal forma que los problemas parecen tener una carácter inopinado o sobrevenido, no hay muchas cuestiones realmente novedosas. Y lo que no es en absoluto una novedad es el problema de la temporalidad y la articulación de procedimientos de estabilización evidenciando lo poco que se ha hecho desde que el problema se detectó y pudo advertirse de sus consecuencias. En este sentido, el Informe de la Comisión para el estudio y preparación del Estatuto Básico del Empleado Público no podía ser más claro al respecto:

«Esta dinámica de selección de personal temporal y posterior estabilización de los empleados temporales al cabo de unos años está poniendo seriamente en cuestión todo el sistema constitucional de garantías relativo al acceso al empleo público e inclusive está llevando a la quiebra otros elementos del propio sistema, como la misma oferta de empleo público, con la garantía de publicidad que supone.

Hay que recalcar que el fenómeno que ahora criticamos se está produciendo no obstante las reiteradas sentencias contrarias de nuestros más altos Tribunales y sin justificación jurídica alguna. Pues, si bien la Comisión considera -y así ha quedado claro en otra parte de este Informe- que debe reducirse la temporalidad en el empleo público y consolidarse en mayor medida el empleo estable, una cosa es la "consolidación de los empleos" y otra muy distinta la subjetiva o particular de aquellos empleados que se han integrado en la Administración por procedimientos excepcionales y escasamente competitivos, gozando de una situación de privilegio frente a otros posibles interesados» (Comisión para el estudio y preparación del Estatuto Básico del Empleado Público, 2005, p. 90).

Estas cuestiones habrán de ser abordadas con mayor detenimiento en los siguientes apartados, interesando, en este momento, destacar los efectos de la elevada temporalidad del empleo público y la articulación de procedimientos de estabilización general.

Se puede admitir acríticamente, como ha hecho el Gobierno y el legislador, el pragmatismo de convertir la temporalidad en estabilidad superando de una vez la problemática jurídica generada por la jurisprudencia generada por la Directiva 1999/70² y su alcance en relación al abuso de la temporalidad, dando además respuesta a la necesidad de alcanzar una Administración más eficaz. La ley lo puede todo, pero formalizar la decisión adoptada no resulta sencilla cuando las reglas constitucionales del modelo de función pública son tan claras y los antecedentes normativos y regulación vigente resultan igualmente meridianos, debiendo además asegurar una cierta estética de integridad o respeto al Estado democrático y de Derecho.

Efectos que se muestran en todos y cada uno de los colectivos afectados, víctimas de una situación que, como se ha anticipado y se verá con mayor detenimiento, resulta incomprensible desde el más elemental cumplimiento de la legalidad $Y$ pudiendo sorprender el hecho de haberse mantenido en el tiempo un estado de incumplimiento tan llamativo, sorprende aún más la manera acrítica e intencionadamente ignorante con la que dichos efectos son asumidos por parte de todos los afectados. Resignada asunción como inevitable

1 Paradójicamente mientras la tasa de temporalidad se reduce sensiblemente en el sector privado y las autoridades laborales junto a los representantes sociales se plantean como un objetivo de atención preferente la reducción e la temporalidad en el mercado laboral privado, en el ámbito público la tasa se ha ido incrementando hasta alcanzar la reconocida por el propio Gobierno en el Real Decreto-ley 14/2021 que la sitúa cercana al $30 \%$ del total.

2 Directiva 1999/70/CE del Consejo, de 28 de junio de 1999, relativa al Acuerdo marco de la CES, la UNICE y el CEEP sobre el trabajo de duración determinada. 
consecuencia del «normal» funcionamiento de las Administraciones Públicas en la gestión de sus recursos humanos Un mal de todos del que nadie es responsable.

Pero los efectos son los que son, y ahí están todas las víctimas del desacierto organizativo esperando la reparación concretada en el Proyecto de Ley de medidas urgentes para la reducción de la temporalidad en el empleo público (procedente del Real Decreto-ley 14/2021, de 6 de julio).

Reparación que, haciendo bueno el dicho de que el papel todo lo soporta (la ley puede con todo, recordemos) en realidad se trata del blanqueamiento, algo fariseo, de un borrón general con responsables concretos que van a resultar indemnes y que, además, en sus consecuencias jurídicas y económicas, presenta una imagen de la Administración muy alejada de los perfiles de estabilidad y profesionalidad que debería acreditar.

Una Administración acorralada por una secuencia de fallos judiciales que, obligando a dar respuesta a situaciones de temporalidad inasumibles e improrrogables, le pone delante de un escenario lamentable en todos los sentidos al que debe enfrentarse de la peor manera posible.

Y no son pocas las víctimas del desacierto organizativo como, seguidamente se podrá comprobar, pero aunando a todas, es el interés general la gran víctima de una situación que nunca debió haberse generado. Y no sólo hay que pensar en los efectos inmediatos desde una perspectiva constitucional, de simple legalidad ordinaria o de trazado de líneas de esfuerzo hacia la estabilidad y profesionalidad administrativa como fundamento de una correcta gobernanza que contribuye a la consolidación y mejora del sistema democrático y de Derecho tal cual se ha expuesto en el primer epígrafe del trabajo.

La magnitud del problema de la temporalidad en el ámbito público confirma la regla no escrita de la prevalencia un tolerado incumplimiento frente al cumplimiento cuando la indiferencia y el paso del tiempo son aliados de la inobservancia para que se alcance la suficiente magnitud y se justifique la adopción de medidas que, bajo el fino velo de su consideración como extraordinarias, deberían repugnar a cualquiera que se preocupara mínimamente por la salud del Estado democrático y de Derecho.

Y como se ha indicado, el problema de la temporalidad del empleo público en España ha llegado a tal nivel que se ha optado por la técnica ya conocida en el sistema de empleo público para resolver el problema de las relaciones de empleo temporal o interinidades: la convocatoria de las plazas para su provisión permanente a través de procesos de consolidación o estabilización, muy acertadamente calificados como procesos selectivos «blandos» ${ }^{3}$.

Procesos asumidos por la totalidad de fuerzas políticas y sindicales de manera absolutamente acrítico, que igualmente han sido asumidos con completa naturalidad por la sociedad.

Sin duda, primando el pragmatismo frente al primor jurídico-democrático, no cabe otra solución que la que se debe tomar ante las cosas no se hacen bien durante mucho tiempo: la respuesta reactiva ante una situación insostenible. Respuesta lenitiva aceptada por todos que, al menos, debería generar una reflexión general con perspectiva de futuro en orden a no repetir los mismos errores y omisiones que han conducido a un quebranto del interés general expresad en no pocos ámbitos o víctimas que no por silenciosas y resignadas limitan la gravedad de lo que se ha hecho y sus consecuencias.

\subsection{El personal temporal como víctima y victimario}

Víctimas son, en primer lugar, el personal temporal, en gran medida los funcionarios interinos al padecer la incertidumbre de la temporalidad. Sufridores de una potestad organizatoria mal ejercida o, en mucho cosas, escondida en el cajón del correspondiente órgano superior de personal que prefería no ejercer la responsabilidad que le era propia para dedicarse a otras cuestiones que en su desacertado juicio le resultaban más sencillas o le podían aportar mayor rendimiento político sometiendo la oferta de empleo público y su desarrollo, a cálculos y mediciones político-electorales cuando no a la molicie administrativa basada en mantener un funcionamiento de la organización basado en la inercia, o a la más absoluta indiferencia frente a una situación que, en el corto plazo de su mandato de apenas cuatro años, su continuidad no le suponía ningún problema.

No dejan de llamar la atención las razones con las que en el Preámbulo al Real Decreto-ley 14/2021, de 6 de julio, de medidas urgentes para la reducción de la temporalidad en el empleo público y el posterior Proyecto

3 Para Boltaina Bosch, los procesos selectivos «blandos», cuya autoría corresponde al profesor Rafael Jiménez Asensio, se refieren a todo un conjunto de procesos de «selección» o, incluso, de «ausencia de selección» que afectan (y en ocasiones gravemente) al empleo público desde los mismos inicios del sistema democrático (Boltaina Bosch, 2018, pp. 140-155). 
de Ley, tratan de justificar la necesidad de adoptar las medidas extraordinarias para hacer frente la situación de temporalidad generada. De todas ellas, el reconocimiento de una continuada mala praxis procedimental en materia de selección personal como determinante del recurso al nombramiento de personal interino y a la contratación de personal temporal como «alternativa organizativa» causa, cuando menos, un cierto sonrojo.

Personal temporal y funcionarios interinos víctimas que, con el paso del tiempo y la forja que otorga el sufrimiento, han ido consolidando su situación para mutar, sin saberlo y sin intención, en victimarios del principio de mérito y capacidad (artículo 103.3 CE) y del derecho de libre acceso a funciones y cargos públicos (art. 23.2 CE).

Y es que, a la vista de las propuestas normativas elaboradas por el Gobierno y el legislativo, el paso del tiempo (situación de abuso) ha convertido las expectativas de estabilidad de este personal en un auténtico derecho subjetivo que se hace eficaz a través del acceso a una plaza pública, lo cual se compadece bastante mal con los precitados principios modulares del empleo público en España y la otra cara de la moneda representada por los derechos de cualquier ciudadano interesado en dichos puestos ${ }^{4}$.

Con toda razón, eso es incuestionable, este personal temporal, estos interinos, reclaman una solución que, desde el pragmatismo que trae causa en la cuantificación de su porcentaje respecto al conjunto de empleados públicos, pasa por la relativización de los principios de mérito y capacidad. En otras palabras, son tantos y su desempeño afecta de mamera tan intensa a la prestación de servicios públicos esenciales (base pensar en la educación y la sanidad) que la consolidación de sus puestos a través de procedimientos ad hoc se ha asumido, por el ejecutivo primero y posteriormente por el legislador, como la única respuesta posible.

En todo este proceso, los citados principios constitucionales no quedan bien tratados pero en ello nada tiene que ver el personal temporal afectado. Ellos suponen la imagen, la representación tangible del maltrato constitucional pero no son más que el resultado final de los desaciertos y la mala praxis en materia de personal.

\subsection{Aspirantes a funciones y cargos públicos: el difícil equilibrio de la consolidación extraordinaria con los principios de mérito y capacidad, y libre acceso a funciones y cargos públicos}

Ante el astillamiento de los dos grandes principios del modelo constitucional de empleo público consagrados en los artículos 103.3 y $23.2 \mathrm{CE}$, son víctimas directas todos aquellos ciudadanos que se preparan para ser los mejores y resultar reclutados por la Administración tras el desarrollo de los oportunos procedimientos de selección. Colectivo de aspirantes a trabajar en la Administración que observan con callado estoicismo, casi religioso, cómo muchas de las plazas a las que aspiraban nunca van a integrar una oferta de empleo público o, al menos, una oferta de empleo público de libre acceso tal y como prevé el citado artículo 23.2 CE configurando dicho acceso como un derecho fundamental.

En este sentido, cuando el Gobierno elaboró y publicó el Real Decreto-ley 14/2021, de 6 de julio, de medidas urgentes para la reducción de la temporalidad en el empleo público a través de la habilitación prevista en el artículo $86 \mathrm{CE}$, pese a los esfuerzos que realizó en su Preámbulo, puede convenirse que no resultó muy escrupuloso respecto a la limitación que la propia norma constitucional establece al prohibir afectar a los derechos, deberes y libertades de los ciudadanos regulados en el Título I. Espacio constitucional en el que se ubica el artículo 23.2. Previsión constitucional que, a todas luces, se ha visto fuertemente afectado por el problema de la temporalidad y la solución planteada a través de los procesos de estabilización.

Sistema de estabilización general respecto al que tanto el Real Decreto-ley 14/2021 como la posterior Ley (proyecto de ley en el momento de redactarse este trabajo) aseguran garantizar los principios de libre

4 Fuentetaja Pastor sintetiza con gran claridad, el debate generado en el Tribunal de Justicia de la UE en relación a la respuesta que habría de darse a la temporalidad a través de procesos ad hoc de estabilización/consolidación.

Al hilo de la Sentencia Sánchez Ruiz de 19 de marzo de 2010, recuerda la posición del Tribunal de Justicia acogiendo el argumento de la Abogada General de que, por mucho que los funcionarios interinos objeto de abuso puedan participar en los procesos selectivos convocados específicamente para poner fin a dicho abuso (situación de temporalidad), no resulta una solución idónea habida cuenta de la escasa seguridad sobre su convocatoria y los inciertos resultados del proceso al estar abiertos a candidatos que no han sido víctimas del abuso de la temporalidad.

De manera más precisa, la Abogada General, desde la perspectiva del personal afectado (dimensión subjetiva) se inclina por procesos de consolidación en los que se tenga en cuenta la situación de abuso padecido.

Para el autor, esta posición es difícilmente cohonestable con los principios de igualdad, mérito y capacidad (Fuentetaja Pastor, 2020, 215-216). 
concurrencia, igualdad, mérito, capacidad y publicidad. Pero dichas garantías, perfiles constitucionales a los que se debe ajustar cualquier tipo de procedimiento de selección, únicamente se extiende al limitado universo de los empleados temporales afectados, sin alcanzar al resto de posibles aspirantes que, sin duda interesados, tienen vedada la concurrencia a estos procesos extraordinarios de acceso a una plaza estable en la Administración. Acceso que se desarrolla en unas condiciones muy favorables al limitarse, en la mayoría de los casos, a un simple proceso de concurso de méritos bastante alejado del exigente rigor de un sistema de oposición.

No es fácil acomodar ningún proceso de estabilización, por extraordinario que se presente, con los principios de mérito y capacidad, y libre acceso a funciones y cargos públicos. Cualquier esfuerzo argumental choca una realidad jurídica y fáctica que otorga una gran debilidad a la solución adoptada ya que siempre que haya un aspirante excluido del acceso a un plaza de empleo público por la configuración restrictiva del proceso de selección, existirá quien de manera razonable podrá exigir la efectividad de su derecho fundamental $^{5}$.

Así, volviendo al Real Decreto-ley 14/2021, El juicio político o de oportunidad que realiza el Gobierno para motivar la extraordinaria y urgente necesidad de elaborar una normativa inmediata, establece como prioridad proteger al personal temporal de la Administración e incrementar la eficacia de la Administración otorgando una respuesta al problema de la temporalidad, pero deja atrás el derecho del resto de ciudadanos a acceder a cargos y funciones públicas. Por supuesto no lo desconoce, pero trata de superar lo que sin duda es una importante objeción a los procesos de consolidación (y por tanto a la solución del problema) en la última parte del Preámbulo apuntando dos ideas: las previsiones del Real-Decreto-ley no afectan a al contenido o elementos esenciales del artículos 23.2 y sus efectos tienen un alcance limitado al no establecer un régimen general de acceso a la función pública.

Frente al argumentario gubernamental, cabrían, al menos dos objeciones inmediatas:

En primer lugar, sí se está afectando el contenido esencial del derecho previsto en el artículo 23.2 por cuanto, debe repetirse pese a la obviedad, es un acceso parcial, limitado y excluyente poco alineado con la doctrina constitucional que lo configura como un derecho fundamental a acceder a las funciones públicas en condiciones de completa igualdad.

De alguna forma, con el planteamiento de los procesos de consolidación y en concreto con éste que nace con la vocación de ser el último y definitivo, se observar una cierta erosión de la doctrina constitucional sobre la obligatoriedad de que las convocatorias de concursos y oposiciones se establezcan en términos generales y abstractos y no mediante referencias individualizadas y concretas ${ }^{6}$.

En segundo lugar, el alcance de la decisión relativa a los procesos de estabilización no es precisamente limitado ya que la necesidad y urgencia del Real Decreto-ley se justifica en las elevadas cifras de temporalidad que, en puridad, son plazas que debían haber sido ofertadas públicamente. La merma a lo que podía haber sido la oferta de empleo público como canal para la efectividad del derecho de acceso a funciones y cargos públicos es muy significativa.

La Sentencia del Tribunal Superior de Justicia de Aragón, Sala de lo Contencioso-administrativo, Sentencia de 16 de marzo de 1990 (Ponente: Juan Piqueras Gayo) en relación a la combinación de los principios de mérito y capacidad con los procedimientos de selección orientados a personal interino, no puede resultar más oportuna en orden a ilustrar la inquietud planteada:

«....atendiendo a los principios legales y constitucionales, es claramente factible arbitrar fórmulas en que se conjuguen los diversos -y en ocasiones contrapuestos- intereses en juego, pues tan legítimos son los derechos del personal interino como de los ciudadanos que, con el único bagaje de su esfuerzo y mérito en la preparación aspiran a acceder a un puesto de servicio o función pública mediante la concurrencia a la oportuna convocatoria» (Fundamento jurídico quinto $)^{7}$.

5 En este sentido resulta de especial interés la STC 27/2012 de 1 de marzo, al definir los procesos cerrados o restringidos (que, según la jurisprudencia constitucional se han admitido solamente en supuestos excepcionales) como aquellos en los que para tomar parte en los mismos se exige haber prestado previamente servicios profesionales en la Administración convocante.

6 SSTC 42/1981, 30/1986, 42/1986, 50/1986 y 50/1986, entre otras.

Al hilo de esta sentencia, resulta muy significativo que en los primeros años del periodo de vigencia de la CE se fuera jurídicamente más cuidadosos con este tipo de temas de lo que en la actualidad se percibe. Así, por ejemplo, se pone de manifiesto en la la Sentencia del Tribunal Supremo, Sala Cuarta, de lo Contencioso-administrativo, de 22 de julio, 1986 (Ponente Aurelio Botella Taza) al solicitar respeto y efectividad al precitado artículo 23.2, mostrando una sensibilidad que ahora, es posible, no se alcanza. 
Por su parte, el Proyecto de Ley, desde la habilitación que le otorga su rango normativo, no se detiene tanto como la normativa de urgencia para justificar su compatibilidad con los artículos 23.2 y 103.3 , pero, igualmente, el legislador no desconoce la necesidad de justificar el encaje de una convocatoria de empleo público limitada a un colectivo concreto definido por su carácter temporal, con el principio de libre acceso.

Es aquí donde el legislador al establecer las condiciones que, de acuerdo con la doctrina constitucional, deben verificarse para que no exista infracción alguna del principio de igualdad de acceso a funciones y cargos públicos, presenta una clara fragilidad en sus planteamientos. Sucintamente, si dichas condiciones son: existencia de una situación excepcional, acudir al procedimiento elegido por una sola vez y regulación en una norma con rango de ley, al menos, respecto a las dos primeras es posible cuestionar su cumplimento a la vista de los antecedentes que fácilmente se identifican.

$Y$ es que, considerando la excepcionalidad de la medida a adoptar con fundamento en la singular, puntual y transitoria necesidad de tener que poner en funcionamiento una nueva forma de organización, no es la primera vez que se acude a un proceso de estabilización tal y como reconoce el Real Decreto-ley 14/2021 y posteriormente el propio Proyecto de Ley aludiendo a los iniciados en los años 2017 y 2018 derivados de las Leyes de Presupuestos Generales del Estado con fundamento en la Disposición Transitoria Cuarta del Real Decreto Legislativo 5/2015, de 30 de octubre, por el que se aprueba el texto refundido de la Ley del Estatuto Básico del Empleado Público.

La solución respecto a la temporalidad basada en procesos de estabilización extraordinaria no puede ser considerada novedosa, más bien es una reiteración ahora cualificada por la magnitud de los afectados y su aplicación general. No hay nada excepcional, es normalidad subida de tono por la gravedad de la situación debido a los inadmisibles niveles de la tasa de temporalidad.

De ello, de esa contradicción, se manifiesta de manera inequívoca el incumplimiento de la doctrina constitucional sobre el art. 23.2 CE como especificación del principio de igualdad que consagra el art. 14 CE. y, muy especialmente, la que declara la inconstitucionalidad de la integración automática en la función pública de carrera del personal temporal por el simple ministerio de la ley, sin superar pruebas selectivas algunas, aunque fueran específicas o de turno restringido ${ }^{8}$.

Pero no sólo el respeto al principio de libre acceso genera inquietud jurídica. La garantía de mérito y capacidad también resulta cuestionable al darse por bueno el mayor mérito y la superior capacidad de cualquiera que acredite la temporalidad como simple referencia cronológica frente a cualquier otro aspirante que no pueda evidenciar la circunstancia de la temporalidad. Lo cual supone una presunción que el legislador, sin decirlo expresamente, parece configurar como iure et de iure.

Esencialmente, en un proceso de limitada competitividad, desde una posición de objetivo privilegio, el empleado temporal acredita a través de su propia antigüedad (sin olvidar el abuso que entraña) que es el mejor para trabajar en el ámbito público. Lo cual supone asumir un riesgo importante ya que, como señalaba en 2005 el Informe de la Comisión para el estudio y preparación del Estatuto Básico del Empleado Público (constatando en aquella fecha el problema de la temporalidad) «el reclutamiento de empleados temporales no exige las mismas garantías, sea en virtud de los procesos consiguientes de consolidación o estabilización del empleo público, que suponen en la práctica integrar, mediante cursos breves o pruebas muy simples, como personal fijo, en su mayor parte funcionario, a empleados que en su día fueron nombrados o contratados sin una verificación rigurosa de sus méritos y capacidades o sin ningún tipo de selección abierta» (Comisión para el estudio y preparación del Estatuto Básico del Empleado Público, 2005, pp. 89-90).

En un procedimiento de consolidación que, de entrada, se define por su amplio ámbito subjetivo, es inevitable que se generen dudas y alguna sospechas que, sin poder generalizar, inciden en la falta de integridad detectada en algunos procedimientos de selección.

Tratando de evitar las meras sospechas sin fundamento o los chascarrillos mal intencionados, Fernández Ramos apunta al Informe para la modificación de la Ley 10/2010 de 9 de julio, de la Generalitat, de Ordenación y Gestión de la Función Pública Valenciana, elaborado por una Comisión presida por el Profesor Sánchez Morón (gran especialista en la materia) para afirmar «que el reclutamiento del personal temporal al

8 La STC 302/1993 de 21 de octubre recuerda, a través de la doctrina recogida en la Sentencia 27/1991, de 14 de febrero que la previsión legal de pruebas específicas para consolidar una situación precaria precedente no lesiona los arts. 23.2 y 103.3 de la Constitución, cuando deriva de un proceso único e irrepetible de creación de una nueva forma de organización de las Administraciones públicas... (Fundamento Jurídico segundo). 
servicio de la Administración Pública elude con mucha frecuencia los procedimientos ordinarios de acceso, entendiendo por tales los de acceso directo a la condición de funcionario de carrera o contratado fijo mediante oposición o concurso-oposición libres» (Fernández Ramos, 2017)9.

A mayor abundamiento, Boltaina Bosch afirma que «ciertamente, durante muchos años, nadie sabía cómo se incorporaba el personal no permanente a las Administraciones públicas, especialmente las autonómicas y las locales. Este periodo fue especialmente relevante en la construcción del Estado autonómico y también al inicio -y años posteriores- de los Ayuntamientos democráticos. Con posterioridad, el modelo se ha ido haciendo más público y aparentemente transparente, pero no son pocas las bases de convocatorias de personal interino/temporal y bolsas de trabajo que priman aspectos que poco o nada tienen que ver con el mérito» (Boltaina Bosch, 2018, pp. 143).

Todo lo expuesto, no cuestiona la necesidad y la urgencia de responder a una situación insostenible que pone en grave riesgo el correcto desenvolvimiento de los servicios públicos al resultar muy compleja la gestión de unos recursos humanos condicionados por una tasa de temporalidad tan elevada.

Tampoco se trata de trasladar ninguna responsabilidad al personal temporal; ellos, como se ha dicho, son víctimas del desacierto organizativo.

Pero las opciones legislativas no se limitan a la regulación de un proceso cerrado de estabilización general absolutamente desigual para los aspirantes a una plaza pública, poco compatible con el contenido esencial de los artículos 23.2 y 103 CE y la doctrina del Tribunal Constitucional al respecto proscribiendo las patentes que lleguen a «excluir la vigencia de estos preceptos constitucionales ni siquiera temporal y excepcionalmente, puesto que nada permite al legislador estatal o autonómico transgredir los límites que la Constitución impone a su libertad de configuración normativa y menos cuando está en juego un derecho con rango de fundamental como es la igualdad de acceso de todos los ciudadanos a las funciones públicas (art. 23.2 de la Constitución). Igualdad de trato que en el Estado de Derecho constituye, desde la perspectiva institucional, uno de los fundamentos objetivos del orden jurídico que aquél reclama, en cuanto es un ineludible corolario de la igualdad ante la Ley, frente a los sistemas vigentes en organizaciones históricas anteriores, donde eran frecuentes toda clase de restricciones por diversas causas e, incluso, la compraventa y patrimonialización de los oficios públicos» ${ }^{10}$.

Ahora bien, siendo esto cierto, no lo es menos que no por eso dejan de jugar los principios de mérito y capacidad en el acceso a la función pública que la Constitución consagra en su art. 103.3, principios que concretan y articulan el genérico juicio de igualdad en esta materia consagrado por el art. 23.2. La promoción interna de los funcionarios a través del trabajo no puede confundirse con una patente para.

Los cambios y las respuestas eran necesarias ante una situación calificada insostenible, por supuesto, pero asegurando a todos los afectados un mejor sistema de amortiguación de efectos y, por extensión, al sistema democrático y de derecho.

\subsection{El empleado público como víctima}

Igualmente pueden considerarse víctimas los actuales empleados públicos de la Administración, personal laboral fijo y funcionarios de carrera que en su día, trazando un imaginario iter de su vida profesional, accedieron a la Administración superando un proceso de concurrencia competitiva y, seguramente, procedimientos internos de promoción. Ahora son igualados por quien no ha tenido que recorrer ese camino (el suyo ha sido otro, el que la autoridad competente le marcó) y llega al mismo punto en la trayectoria profesional con efectos en aspectos tan sensibles para cualquier empleado público como la antigüedad, la provisión de puestos, la carrera profesional etc.

En lo tocante a la posición de los empleados públicos frente al problema de la temporalidad y los procesos extraordinarios de estabilización, es oportuno recordar que el derecho fundamental del artículo 23,2 no solo tiene efectividad en el momento inicial de acceso a la función pública, sino que se proyecta durante toda la relación funcionarial. Como señala Beladiez Rojo «de este derecho fundamental no se derive solo un

9 El mismo autor recuerda los agudos comentarios de Nieto (2003) expresados en la recensión al libro de Joan Mauri Majós: "¿Pueden ponerse puertas al campo? ¿Es posible encerrar el humo en una jaula? Yo creo que no; como tampoco creo que puedan controlarse eficazmente las selecciones irregulares de funcionarios. Convicción personal que no obsta, bien es verdad, a que los poderes públicos tengan el deber de regular con cuidado estos procedimientos para evitar en lo posible -ya que no eliminar del todo ni corregir ejemplarmente- las lamentables prácticas que, en este caso, con escandalosa frecuencia se practican...».

10 STC 302/1993 de 21 de octubre, Fundamento Jurídico segundo. 
derecho a ingresar en la función pública en condiciones de igualdad, sino que también se encuentra garantizado por el mismo el derecho al desarrollo o promoción de la carrera administrativa en esas condiciones» (Beladiez Rojo, 2018, p. 705).

\subsection{Los ciudadanos como víctimas indolentes}

También pueden ser considerados víctimas los ciudadanos, por el impacto que las disfunciones en el sistema de empleo público, han tenido y tiene sobre los servicios públicos que conforman su espacio de dignidad o, en términos constitucionales, su Estado del Bienestar. Víctimas que, en realidad no tienen conciencia de su condición, indiferentes por puro desconocimiento de los beneficios que les generaría unas Administraciones Públicas asentadas en un empleo estable y profesional apalancado en el principio de mérito y capacidad.

Sistema de empleo, muy mejorable en lo tocante a la temporalidad, que los ciudadanos financian a través de sus impuestos sin preocuparse demasiado, por el correcto empleo de su esfuerzo fiscal.

En un entorno jurídico-político como el que se vive en los últimos años, la mirada de los operadores y responsables en la adopción de decisiones públicas de carácter legislativo y/o ejecutivo resulta, en la mayoría de los casos, interesadamente jerárquica, decidiendo de manera unilateral qué líneas de esfuerzo resultan más atinadas para la democracia.

La enorme indiferencia ciudadana ha definido un espacio político en el que el interés público se ha convertido en un simple recurso argumental bastante alejado de una auténtica materialización práctica a través de decisiones y actos elevados sobre cualquier tipo de provecho partidista, clientelar o particular.

Buen ejemplo de ello es que, en esta ordenación jerárquica, la organización administrativa no se encuentra precisamente en los primeros puestos de preocupación, por cuanto las políticas o actuaciones sobre la materia, reiterando la idea, es absolutamente indiferente a la ciudadanía.

Salvo algunos aspectos muy anecdóticos o puntuales integrantes del gran sistema de medios y recursos que una Administración ordena para alcanzar los fines que le son propios, incluyendo la definición de su propia estructura, los ciudadanos carecen del conocimiento necesario (o no se le quiere proporcionar) para dimensionar la radical importancia de la organización administrativa y la escora que está teniendo hacia una completa discrecionalidad cuando no, arbitrariedad. Y muy tristemente, se asume el mal funcionamiento organizativo como general y naturalizado en lo público.

Centrándonos en el tema que nos ocupa, es muy posible que los ciudadanos, a través de los medios de comunicación o por iniciativa de algún representante electo en la oposición, muestren interés, por ejemplo, por el personal eventual, su número, su nombramiento, los sueldos de éstos y de los cargos electos que les nombraron. No hay que restarles importancia a estas cuestiones ya que suponen una buena muestra del aprecio hacia los público y el valor que se le otorga. Pero, en el conjunto de la organización administrativa, debe convenirse que es una parte menor o, al menos, no determina por sí misma el desarrollo y la prestación de servicios públicos. Por el contrario, las decisiones en materia de personal, las políticas de empleo público, se anudan directamente al desarrollo de los servicios públicos y a la calidad de su prestación.

El Proyecto de Ley de medidas urgentes para la reducción de la temporalidad en el empleo público procedente del Real Decreto-ley 14/2021, de 6 de julio (que, muy posiblemente, ya esté aprobado al momento de publicarse este trabajo) así lo reconoce en su Preámbulo afirmando que la modernización y mejora de la calidad de los servicios públicos «no se pueden alcanzar sin una adecuada gestión del principal activo con el que cuenta la Administración, como es su capital humano. La mejor gestión del empleo al servicio de las distintas Administraciones Públicas exige, sin duda, disponer de políticas coherentes y racionales de dotación de efectivos de carácter permanente, que cubran las necesidades reales de los servicios y limiten la temporalidad a la atención de necesidades de carácter estrictamente coyuntural».

Pese a la radical importancia del personal en el desarrollo y calidad de los servicios públicos pocos son los que se preguntan por su gestión y organización. Pocos se preguntan por las ofertas de empleo público, su publicación, si acompañan ordenadamente al año en curso, por el desarrollo de las pruebas, o la racionalización de los recursos humanos de la Administración.

En la tramitación del Real Decreto-ley 14/2021, de 6 de julio y posterior Proyecto de Ley de medidas urgentes para la reducción de la temporalidad en el empleo público se reconoce sin empacho alguno una serie de prácticas alejadas de los perfiles de comportamiento establecidos por las previsiones normativa sobre la materia que serán analizados más adelante. 
Tanto por parte del Gobierno al redactar el Real Decreto-ley 14/2021 como después el legislador al elaborar la norma con rango de ley asumen auténticos incumplimientos legales que se han mantenido durante años:

- No convocar de manera periódica y sistemática, preferentemente con carácter anual, las plazas vacantes, para su provisión definitiva.

- Insuficiente utilización de la planificación estratégica en la ordenación del empleo público.

- Lentitud y dilación en el desarrollo de los procedimientos de selección de personal.

Pues bien, reconocer estos incumplimientos no ha supuesto ningún tipo de crítica, ni de autocrítica, pasando completamente desapercibido para el conjunto de la ciudadanía.

La organización administrativa, el empleo de la potestad organizatoria, ha acabado residenciada en uno de los niveles más desconocidos del ejercicio del poder, quedando, de hecho, al exclusivo criterio de quien a través de su legitimación democrática recibe la correspondiente habilitación administrativa a través de la citada potestad.

En un ámbito en el que el Derecho exige la motivación como garantía, elemental control frente a las inmunidades del poder (recordando el pilar doctrinal que representa el trabajo de García de Enterría ${ }^{11}$ ) las decisiones organizatorias se toman ayunas de cualquier explicación, en ningún caso técnica, pero, en muchas ocasiones, tampoco aportando los motivos de idoneidad política.

\section{LA TEMPORALIDAD COMO ALTERNATIVA ORGANIZATIVA IMPROPIA}

Confirmando la escasa novedad del problema de la temporalidad y su solución, las razones de este problema y su elevada tasa vienen a ser en el año 2021 las mismas que en el año 2005.

Esto es, los factores que identificaba el Informe sobre temporalidad en el empleo público elaborado por el Consejo Económico y Social en el año 2005, resultan completamente coincidentes (incluso en su literalidad) a los expresados tanto por el Real Decreto-ley 14/2021, de 6 de julio, de medidas urgentes para la reducción de la temporalidad en el empleo público como el posterior Proyecto de Ley, en su Preámbulo: factores de carácter presupuestario y factores relacionados «con la insuficiente utilización de la planificación estratégica en la ordenación del empleo público, así como la falta de regularidad de las convocatorias y procedimientos de selección de personal para la cobertura de vacantes con carácter definitivo».

Tipología de factores que ayudan a enfocar y, sobre todo, ordenar algunas ideas que el tiempo ha hecho olvidar y que, tal vez, puedan contribuir a esa reflexión de futuro que se apuntaba en el anterior epígrafe.

\subsection{El factor presupuestario como causa de la temporalidad}

Por lo que se refiere a los factores de tipo presupuestario, sólo desde la consideración de la temporalidad como un subterfugio (válvula de escape según algunos autores ${ }^{12}$ ) para eludir las restricciones para la dotación de nuevas plazas, en un entorno de absoluto desafecto y desafío a todas las reglas de disciplina presupuestaria y empleo, puede llegar a entenderse su abusivo uso como técnica organizativa.

Buena parte del argumentario con el que se trata de justificar la elevada tasa de temporalidad en el empleo público se asienta sobre razones que, de una manera u otra, enlazan con la idea de asegurar la prestación de servicios públicos de acuerdo a unos mínimos estándares de calidad. Mantener el ideal políticodemocrático del servicio público ininterrumpido y de calidad ha justificado el incumplimiento de las reglas en materia de personal y, por extensión, las presupuestarias.

Pero esta motivación resulta inaceptable desde la perspectiva apuntada en el segundo epígrafe de este trabajo relativa a la consideración global de la gestión pública de tal manera que el servicio público, como actividad prestacional de la Administración, como institución integradora de la idea de Administración Pública, no puede entenderse de manera aislada, estanca al resto de elementos configuradores del concepto síntesis de Administración Pública. Y mucho menos puede suponer el perfecto comodín para el incumplimiento por cuanto, por sí misma, la inobservancia normativa en materia de empleo y presupuesto redunda de manera negativa en el conjunto de la Administración y, consecuentemente, en la prestación de los servicios públicos.

11 García de Enterría (1962, p. 38).

12 Vid. entre otros, Martín Toro (2019, p. 127). 
Recurrir a la temporalidad para tratar de cumplir con las exigencias de disciplina presupuestaria y así cubrir las necesidades de personal no parece que sea, como así se ha demostrado, un modelo de gestión pública adecuado. El propio gestor público se hace trampas a sí mismo.

Todo lo expuesto sin entrar a valorar el acierto y oportunidad de ese incremento de las necesidades de personal derivadas, en gran medida, de la implementación de nuevas políticas públicas basadas en el imparable incremento de las prestaciones que igualan servicios básicos a servicios meramente ideológicos.

A la vista de todo lo expuesto, desde la consideración de los factores presupuestarios como causa, el desvalor de la temporalidad como técnica alternativa en la organización del personal, resulta doble y una vez más, muestra con durísima claridad, el escaso nivel técnico y la nula lealtad al sistema de quienes han estado tomando decisiones en materia de personal.

\subsection{El consentimiento de la mala organización como determinante de la temporalidad}

En lo tocante a los factores de tipo organizativo vinculados a la planificación estratégica en la ordenación del empleo público y la regularidad de las convocatorias, el relato que se genera a la vista del histórico de la normativa sobre la materia evidencia una situación de inobservancia que tanto el Gobierno como el legislador no tiene más remedio que reconocer:

«La experiencia acumulada nos presenta, por tanto, una realidad que se aleja de la deseable y que nos separa, en este campo, del modelo de función pública diseñado por el constituyente y por el legislador».

A partir de este reconocimiento, Gobierno y legislador se esfuerzan por tratar de justificar lo injustificable, aludiendo entre otros argumentos a la incidencia (en el año 2021) del Acuerdo marco sobre el trabajo con contrato de duración determinada, que figura en el anexo, celebrado el 18 de marzo de 1999 entre las organizaciones interprofesionales de carácter general (UNICE, CEEP y CES) expresado en la Directiva 1999/70/CE del Consejo, de 28 de junio de 1999 que en lo que más convence es en mostrar una imagen laboral del empleo público que resulta incompleta y conflictiva tal y como ha evidenciado la jurisprudencia europea y nacional sobre la materia ${ }^{13}$.

Tampoco resulta excesivamente concluyente la alusión que la norma de urgencia realiza al Plan de Recuperación, Transformación y Resiliencia y su evaluación positiva por parte de la Comisión Europea ${ }^{14}$.

Nada convence completamente ya que la separación entre la realidad y el modelo de empleo público cuyas bases arrancan de la misma Constitución no se explica, en apretada síntesis, por el incumplimiento de los principios y condiciones previstos en un Acuerdo marco sobre el trabajo de duración determinada formalizado hace más de dos décadas.

Como tampoco por la renovación, una vez más, de objetivos en relación a la modernización de las Administraciones Públicas expuestos como un eterno ostinato administrativo que se repite de forma consecutiva sin importar ya el momento ni el gobierno que lo plantea. Sin remontarnos muy atrás en el tiempo, baste echar un vistazo al citado Informe sobre temporalidad en el empleo público elaborado por el Consejo Económico y Social en el año 2005 o, unos años después, al Informe sobre Reforma de la Administración (Informe CORA) y su décima propuesta sobre medidas estratégicas en materia de empleo público.

Sería más correcto (honesto) decir o, más bien, reconocer, que el abuso de la temporalidad como técnica organizativa en materia de gestión de recursos humanos en las Administraciones Públicas convirtiendo la provisionalidad en un problema estructural, ha sido completamente intencionado por razones que discurren en paralelo.

Una primera razón, por interés directo en que el modelo de empleo público se sostenga sobre los pilares de la temporalidad. Y ello al objeto de evitar la estabilidad del personal público y, por tanto, su completa profesionalidad como fortaleza de la organización pública cuyos elementos fundamentales han de mostrarse inmunes al sistema de alternancias políticas.

De la debilidad deriva la mayor facilidad de orientación del personal ya que, hay quienes prefieren la lealtad derivada de la vinculación política o la necesidad económica/laboral, a la capacidad técnica y por tanto a la plena profesionalidad que siempre se anuda a la estabilidad.

13 Sobre esta cuestión puede consultarse el ya citado trabajo de Fuentetaja Pastor (2020, pp. 201-230).

14 De acuerdo al Plan de Plan de Recuperación, Transformación y Resiliencia, se establecen 4 ejes transversales (transición ecológica, transformación digital, cohesión social y territorial e igualdad de género) que a su vez se proyectan en 10 políticas palanca, siendo la cuarta la denominada "Una Administración para el siglo XXI" cuyo componente 11 es el dedicado a la "Modernización de las Administraciones Públicas". En este componente encaja el objetivo de reducir la temporalidad del empleo público y mejorar su formación. 
Este razonamiento, no por difícil de probar con elementos categóricos, resulta menos verosímil ya que en un modelo democrático que discurre hacia niveles de menor calidad en sus representantes políticos, se mira con notable desconfianza al empleado público profesional, con criterio técnico y, sobre todo, con la base necesaria para sostenerlo sin temor a ningún tipo presión o intento de modulación.

A la mediocridad política o a quien no cree realmente en la democracia, el empleo público estable y profesional le supone un obstáculo a superar.

Podría decirse que este argumento se contradice con la estabilización del empleo temporal al otorgar un condicionante de profesionalidad básico. Pero no hay contradicción, ya que en esta línea argumental, recuperando lo que señalaba el Informe de la Comisión para el estudio y preparación del Estatuto Básico del Empleado Público, como se sabe, en el año 2005, se ha puesto seriamente en cuestión todo el sistema constitucional de garantías relativo al acceso al empleo público restándole la legitimidad que requiere como pilar democrático.

Una segunda razón, se explica a través de la laxitud en el cumplimiento normativo que no sólo se detecta en este ámbito sino también en otros muchos de la actividad administrativa aunque, sin duda, no alcanza la intensidad que muestra el problema de la temporalidad.

Frente a la simple obligación de cumplimiento de las reglas de selección de personal expresadas en normas específicas, se optó por desconocerlas dejando que cada órgano superior de personal en cada Administración actuara con absoluta libertad según su particular criterio que, obviamente, no era coincidente con el interés general que siempre representa el cumplimiento del principio de legalidad como fundamental obligación de cualquier autoridad o agente público.

Como se verá seguidamente, podría decirse que los órganos superiores de personal han estado narcotizados sin apreciar las señales de peligro que el incumplimiento iba lanzado, empezando por la más elemental como era atender a la estadística comparativa entre personal fijo y personal temporal.

No puede dejar de sorprender que sólo ahora, de repente, se descubriera el riesgo que la temporalidad supone para asegurar la calidad de los servicios públicos, reconociendo que las técnicas organizativas temporales deben reservarse restrictivamente a situaciones coyunturales y urgentes.

En ambos casos, aun cuando es obvio que el desvalor de cada una de las razones apuntadas es distinto, el denominador común a la priorización de la provisión temporal frente a la cobertura ordinaria, es el reconocimiento de un reprochable incumplimiento de la legalidad que, tal cual se apuntaba líneas atrás, la historia normativa sobre la materia se encarga tozudamente de evidenciar.

Bastaría tomar los principales hitos normativos a partir de la publicación de la Constitución de 1978 para evidenciar lo expuesto, pero es insoslayable hacer referencia a la Ley de Bases de 1963 y texto articulado de 1964 ya que, además de prolongar su vigencia ya iniciado el periodo constitucional y ayudar a su consolidación, preveían meridianos principios orientadores para desarrollar una óptima planificación estratégica en la ordenación del empleo público, otorgando la capacidad jurídica necesaria para desarrollarla de acuerdo a los principios de eficacia y celeridad como informadores en la sustanciación de cualquier procedimiento.

La Ley 109/1963, de 20 de julio, de Bases de los funcionarios civiles del Estado, establecía dos importantes bases que, sin duda, marcaban un significativo punto de partida, orientando el camino a seguir, en aquel momento cronológico pero también en la actualidad. Merece la pena su reproducción literal:

\section{«Base VI.}

Uno. Todos los centros y dependencias de la Administración del Estado formarán sus correspondientes plantillas de funcionarios, en las que se relacionarán, debidamente clasificados, los puestos de trabajo de que consten, de acuerdo con las bases que se establezcan por el Consejo de Ministros, a propuesta del Presidente del Gobierno, y que responderán a principios de productividad creciente, racionalización y mejor organización del trabajo que permitan, en su caso, y sin detrimento de la función pública, una reducción de las plantillas con la consiguiente disminución del gasto público.

\section{Base XI.}

Tres. Para nombrar funcionarios interinos será condición inexcusable que no sea posible, con la urgencia exigida por las circunstancias, la prestación del servicio por funcionarios de carrera.

Cuatro. El nombramiento de funcionario interino deberá ser revocado cuando la plaza que desempeñe sea provista por procedimiento legal.». 
Marcada la senda, el Decreto 315/1964, de 7 de febrero, por el que se aprobaba la Ley articulada de Funcionarios Civiles del Estado, desarrolló las bases del modelo sin requerir grandes esfuerzos interpretativos en relación a la planificación de recursos humanos en la Administración Pública, ni tampoco en el tratamiento de la temporalidad concretado en la figura de la interinidad. A saber:

\section{«Artículo 5.2}

Son funcionarios interinos los que, por razón de necesidad o urgencia, ocupan plazas de plantilla en tanto no se provean por funcionarios de carrera.

\section{Artículo 52}

1. La clasificación de los puestos de trabajo se realizará, de acuerdo con las bases que establezca el Consejo de Ministros, a propuesta del Presidente del Gobierno, previo informe de la Comisión Superior de Personal.

2. Las plantillas orgánicas habrán de ajustarse a las necesidades de los servicios, para lo cual serán revisadas cada cuatro años por los respectivos Ministerios, y potestativamente cada dos, teniendo en cuenta principios de productividad creciente, racionalización y mejor organización del trabajo, que permitan, en su caso, y sin detrimento de la función pública, una reducción de las mismas, con la consiguiente disminución del gasto público.

3. Todos los Centros y dependencias de la Administración del Estado formarán sus correspondientes plantillas orgánicas, en las que se relacionarán, debidamente clasificados, los puestos de trabajo de que consten.

4. Las plantillas orgánicas y sus modificaciones se aprobarán por el Gobierno, previo informe de la Comisión Superior de Personal, y se publicarán al fin de cada bienio en el Boletín Oficial del Estado.

\section{Artículo 65}

Los Jefes solicitarán periódicamente el parecer de cada uno de sus subordinados inmediatos acerca de las tareas que tienen encomendadas y se informarán de sus aptitudes profesionales con objeto de que puedan asignarles los trabajos más adecuados y de llevar a cabo un plan que complete su formación y mejore su eficacia.

\section{Artículo 104}

1. Para nombrar funcionarios interinos será condición inexcusable que no sea posible, con la urgencia exigida por las circunstancias, la prestación del servicio por funcionarios de carrera, debiendo justificarse estos extremos ante la Comisión Superior de Personal. El nombramiento deberá recaer en personas que reúnan las condiciones exigidas para el ingreso en el Cuerpo a que pertenezca el puesto de trabajo.

2. El nombramiento de funcionarios interinos deberá ser revocado en todo caso cuando la plaza que desempeñen sea provista por procedimiento legal.

3. Estos funcionarios percibirán el sueldo correspondiente al Cuerpo a que pertenezca la vacante.».

Sin duda, la lectura de este bloque normativo de hace más de medio siglo provoca una cierta perturbación poniendo en evidencia el deficiente trabajo que durante décadas se ha desarrollado en materia de ordenación del empleo público en España.

La exigencia de plantillas ajustadas a las necesidades de los servicios, su revisión (evaluación) cada cuatro años (potestativamente cada dos), las exigencias de productividad y organización en el trabajo como factores para disminuir el número de empleados públicos y, consecuentemente, disminuir el gasto público, contrastan con una realidad que, si bien sería injusto considerar general, queda muy cerca de poder ser calificada como significativamente mayoritaria. Y es que, hasta la jurisdicción contencioso-administrativa tenía muy claro, dentro del absoluto respeto a las garantías de los empleados públicos, la prelación de intereses y la supraordenación de los considerados generales ${ }^{15}$.

15 Entre otras puede citarse la Sentencia del Tribunal Supremo, Sala Tercera, de lo Contencioso-administrativo, Sección 5. ${ }^{\text {, }}$ Sentencia de 3 de octubre de 1978 (Recurso 506.826) en la que, analizando la adquisición de la cualidad de funcionario público de una profesora interina, se establece que el acceso de un interino sin justificación, significaría un exceso en la plantilla del Cuerpo, lo que sería contrario a toda normativa legal y a la finalidad y espíritu de ésta. 
Normas que no se vieron alteradas hasta la Ley 30/1984, de 2 de agosto, de medidas para la reforma de la Función Pública.

Esta Ley, de enorme trascendencia política para el desarrollo y consolidación de la joven democracia española a través de la actuación sobre el modelo de función pública, resultaba de una gran pulcritud jurídica no ya con los renombrados artículos 23.2 y 103.3 CE, sino con la idea de seguridad y certeza jurídica del artículo 9.3 del Texto fundamental.

Desde esta perspectiva, la redacción original de su artículo 18 no puede resultar más correcta como sencilla respuesta normativa al problema de la regularidad de las convocatorias y procedimientos de selección de personal para la cobertura de vacantes con carácter definitivo que ya registró en el año 2005 el Consejo Económico y Social en el citado Informe sobre temporalidad en el empleo público y que dieciséis años después, sorprendentemente, sigue siendo objeto de preocupación para el Gobierno y el legislador.

Señalaba el precitado artículo 18 de la Ley 30/1984, de 2 de agosto, de medidas para la reforma de la Función Pública:

«Artículo 18. La oferta de empleo público.

Las plazas dotadas que no puedan ser cubiertas con los efectivos de personal existentes constituyen la oferta de empleo de la Administración del Estado.

Aprobada la Ley de Presupuestos Generales del Estado, el Ministro de la Presidencia propondrá al Gobierno para su aprobación la oferta anual de empleo de personal al servicio de la Administración del Estado.

La oferta de empleo deberá contener necesariamente todas las plazas dotadas presupuestariamente y que se hallen vacantes, indicará asimismo las que de ellas deban ser objeto de provisión en el correspondiente ejercicio presupuestario y las previsiones temporales para la provisión de las restantes.

La publicación de la oferta obliga a los órganos competentes a proceder, dentro del primer trimestre de cada año natural a la convocatoria de las pruebas selectivas de acceso para las plazas vacantes comprometidas en la misma y hasta un 10 por 100 adicional. Tales convocatorias indicarán el calendario preciso de realización de las pruebas, que, en todo caso, deberán concluir antes del 1 de octubre de cada año, sin perjuicio de los cursos selectivos de formación que se establezcan.

Los Tribunales o las Comisiones de Selección no podrán aprobar ni declarar que han superado las pruebas respectivas un número superior de aspirantes al de plazas convocadas. Cualquier propuesta de aprobados que contravenga lo anteriormente establecido será nula de pleno derecho.».

Las demás Administraciones Públicas elaborarán y propondrán públicamente sus ofertas de empleo ajustándose a los criterios anteriormente expuestos.

Habría que preguntarse por los motivos por los que una norma tan simple pero tanta efectividad para el buen funcionamiento del sistema de empleo público no tardó demasiado en ser suspendida ${ }^{16}$ y posterior-

Por su parte la Sentencia del Tribunal Supremo, Sala Tercera, de lo Contencioso-administrativo, de 9 de mayo, 1986 (Ponente: Fernando Roldán Martínez) caracteriza de manera ortodoxa la figura del funcionario interino, siendo en sí misma una garantía al modelo de función pública y una llamada de atención a todos los interesados: el desempeño de un cargo público por personal interino o provisional no da derecho alguno al recurrente, desde el punto de vista del derecho funcionarial para seguir continuando o desempeñándolo en propiedad, pudiendo la Administración que le designó decretar el cese en el momento en que lo estime oportuno, ya que las garantías legales y reglamentarias de la inamovilidad alcanza exclusivamente a los funcionarios en propiedad y, aunque en el anuncio de la convocatoria o en nombramiento se limite el tiempo o plazo máximo de duración de la interinidad, transcurrido o no ese plazo tope, el ocupante del cargo con carácter provisional no consolida la propiedad del mismo, ya que de interpretar lo contrario equivaldría a conseguir el logro de los empleos públicos por prescripción, sistema no autorizado en las normas legislativas vigentes...

16 Ley 28/1992, de 24 de noviembre, de Medidas Presupuestarias Urgentes. Artículo 4. Suspensión temporal parcial del artículo 18 de la Ley 30/1984, de 2 de agosto, de Medidas para la Reforma de la Función Pública.

A partir del 23 de julio de 1992, y durante el ejercicio 1992, se suspende en el ámbito de la Administración del Estado, de sus Organismos autónomos y de la Administración de la Seguridad Social la vigencia del artículo 18 de la Ley 30/1984, de 2 de agosto, de Medidas para la Reforma de la Función Pública, en lo relativo a la necesidad de que la Oferta de Empleo Público contenga la totalidad de las plazas dotadas presupuestariamente y que se hallen vacantes y a que la publicación de la oferta obliga a los órganos competentes a proceder, dentro del primer trimestre de cada año natural, a la convocatoria de las pruebas selectivas de acceso para las plazas vacantes comprometidas en la misma y hasta un 10 por 100 adicional. 
mente completamente modificada por la Ley 22/1993, de 29 de diciembre, de medidas fiscales, de reforma del régimen jurídico de la función pública y de la protección por desempleo suprimiendo las exigencias de ordenación temporal.

Pero, sobre todo, la cuestión es por qué nadie parece querer recuperar la acertada propuesta del legislador de 1984 que, bien a las claras, cumple con los principios que definen las líneas de la buena administración proyectadas a la gestión de recursos humanos. En primer término, planificación, predictibilidad y transparencia y a partir de estos principios, la proyección hacia el control, la seguridad jurídica y la decidida apuesta por la profesionalidad, formando un cuerpo que otorga efectividad a las exigencias constitucionales de igualdad, mérito y capacidad.

Dejar al arbitrio de cada Administración, como sucede, la publicación de la oferta, el momento de la convocatoria y el desarrollo de las pruebas, como principales actos del procedimiento de selección, incrementa el peligro de hacer ineficaces los principios enumerados, generando una gran inseguridad e incertidumbre a los ciudadanos, indefensos frente a comportamientos públicos indeseables.

La Sentencia 1312/2021 del Tribunal Supremo, Sala de lo Contencioso-administrativo, de 4 de noviembre, 2021 (Recurso 8325/2019) expresa, desde el reconocimiento del derecho a una buena administración, la situación descrita:

«Es cierto que existe legislación adecuada para salvaguardar los derechos del ciudadano ante la inactividad administrativa, procurando una tutela efectiva en tanto posibilita el acceso al control judicial, al respecto los institutos del silencio administrativo o la propia caducidad, o incluso habilitando la impugnación jurisdiccional contra la inactividad administrativa, arts. 25.2 y 29.1 de la LJCA; pero existe un vacío normativo positivo que obvia completamente los cauces para reaccionar contra cierta inactividad administrativa; la actividad diligente y temporánea por parte de la Administración no constituye una potestad discrecional de la misma sometida a su voluntad o conveniencia, al margen, a veces, de los principios y reglas constitucionales y legales, representando potencialmente la imposibilidad de control judicial de la actividad administrativa en contra del mandato constitucional del art. 106.1 de la CE, y quebrando un derecho del administrado que como se ha razonado anteriormente no es mera entelequia sin plasmación y efectividad práctica, como es el derecho a que la actividad de la Administración cuando afecta a sus derechos e intereses se desarrolle y resuelva en un tiempo razonable y proporcionado, esto es, a no sufrir dilaciones indebidas e injustificadas» (Fundamento jurídico séptimo).

La redacción original del artículo 18 de la Ley 30/1984 elevaba la normativa en materia de planificación y gestión del empleo público a unos estándares de corrección y cumplimiento en el proceder de la Administración que, de no haber sido redactada, en la actualidad se celebraría como una acertada y garantista innovación del legislador, favorecedora de la legitimidad y credibilidad de la Administración.

Es cierto que la Ley 22/1993, de 29 de diciembre, de medidas fiscales, de reforma del régimen jurídico de la función pública y de la protección por desempleo, modificó completamente la redacción original del artículo 18 de la Ley 30/84 pero, pese a perder las garantías procedimentales y cronológicas relativas a la planificación de las necesidades de personal y su selección, incorporó la figura de los «Planes de Empleo» definidos como «instrumentos esenciales para el planteamiento global de las políticas de recursos humanos de las distintas organizaciones administrativas que tratan de adecuar el mercado interno de trabajo a las necesidades reales de la propia Administración con el fin de incrementar la eficiencia de la misma».

Esto es, pese a que se perdieron los condicionantes temporales que aseguraban la sistemática y regularidad de las ofertas de empleo público, se mantuvo la idea de ordenación estratégica, de planificación de las necesidades de personal que, de haberse desarrollado correctamente, muy posiblemente hubiera evitado que la temporalidad se convirtiera en el problema que ahora es.

Marco normativo que se mantuvo con la Ley 7/2007, de 12 de abril, del Estatuto Básico del Empleado Público, cuya Exposición de Motivos lanzaba a los órganos superiores de personal mensajes sobre la importancia de la gestión de personal y, consecuentemente, su elevada responsabilidad. Baste recordar:

«Las Administraciones y entidades públicas de todo tipo deben contar con los factores organizativos que les permitan satisfacer el derecho de los ciudadanos a una buena administración, que se va consolidando en el espacio europeo, y contribuir al desarrollo económico y social. Entre esos factores el más importante es, sin duda, el personal al servicio de la Administración». 
Finalmente, cerrando este iter normativo, el vigente Real Decreto Legislativo 5/2015, de 30 de octubre, por el que se aprueba el texto refundido de la Ley del Estatuto Básico del Empleado Público confirma todo lo expuesto.

A la vista de este rápido repaso a las líneas gruesas del diseño de gestión de personal en el ámbito público, se concluye que la mala praxis en la gestión y planificación del personal al servicio de la Administración resulta elocuente, caracterizando como deficiente el trabajo desarrollado por los órganos superiores de personal.

Así, descendiendo a un ejemplo concreto, frente a la claridad y exacta orientación de las normas expuestas, el hecho que durante años se haya considerado una técnica organizativa ordinaria la constitución de «bolsas o listas de interinos» para ir haciendo periódicos llamamientos en función de las necesidades que se pudieran plantear, ofrece un patrón medida del aprecio o entendimiento que se ha tenido a las exigencias de planificación y organización de los recursos humanos y, por extensión, la más que laxa interpretación a los conceptos de necesidad y urgencia como motivadores del empleo temporal y, específicamente, de las interinidades.

Ejemplo de las «bolsas o listas de interinos» que no agota por sí mismo el amplio abanico de opciones organizativas de la temporalidad, unas más escrupulosas que otras con los principios de publicidad y mérito y, por tanto, con la transparencia y el control en el acceso a una función o cargo público.

Recapitulando a modo de conclusión, desde los años 60 hasta la década de los 90, la idea de gestión ordenada y planificada de los recursos humanos de la Administración ha sido una directriz de carácter preceptivo para quienes tenían asumidas competencias superiores en materia de personal. Y ello de manera combinada con la caracterización del recurso al empleo temporal como técnica justificada por la necesidad (en términos de compromiso del servicio público) y la urgencia.

La temporalidad como técnica organizatoria en materia de empleo ha supuesto uno de los mayores incumplimientos normativos de nuestra democracia cuya generalizada tolerancia, además de mostrar un perfil muy bajo de respeto y lealtad consrtituiconal, ha puesto en peligro el modelo de función pública y, por tanto, la fortaleza del propio sistema democrático.

\section{LA DISUASIÓN DE LA TEMPORALIDAD A TRAVÉS DE LA RESPONSABILIDAD: EL ESCALAMIENTO HACIA LA PREVARICACIÓN PENAL}

\subsection{La responsabilidad como rompiente de la impunidad}

Uno de los aspectos que mayor rechazo puede causar a cualquier operador o interesado sensible en la materia, a cualquier ciudadanos en definitiva, es la impunidad de quienes con sus decisiones han provocado el problema de la temporalidad.

Impunidad que no es puntual o aislada. En realidad, la realidad nos muestra que no es infrecuente actuar sin temor o conciencia de las consecuencias. La tendencia a la impulsividad o la espontaneidad en el ámbito público no parece penalizarse democráticamente y, por lo que se ha podido observar hasta el momento al analizar la temporalidad como técnica organizativa, tampoco jurídicamente. Ya lo apuntamos en su momento, la exigencia de responsabilidad en el ámbito público, pensando fundamentalmente en la responsabilidad por desacierto, ha sufrido un proceso de alarmante raquitismo (Nevado-Batalla Moreno, 2021, p. 369).

Una de las grandes diferencias entre la gestión pública y la gestión privada, es que en la actividad pública es posible disfrutar del privilegio de tomar decisiones sin esperar ninguna exigencia de responsabilidad. Y ello pese a que la idea de responsabilidad, de rendición y exigencia, está en la misma esencia del sistema democrático a través del sometimiento al principio de legalidad.

Pero a la vista está que no es así. No es el único sector identificable, pero en el que ahora nos ocupa, el incumplimiento normativo en materia de personal no ha tenido ningún tipo de respuesta, conduciendo al abuso de la temporalidad y sus fatales consecuencias. Y es así, como RIVERO ORTEGA destaca citando a Montesquieu, no hay poder que no incite al abuso (Rivero Ortega, 2020. p. 22).

La impunidad en del desempeño de funciones públicas resulta particularmente llamativa en el ámbito organizativo de la Administración habida cuenta del carácter marcadamente discrecional que tiene la potestad organizatoria y la limitada efectividad que tienen los controles y garantías para su ejercicio. El problema de la temporalidad es un lamentable ejemplo de ello que se evidencia de manera cuantitativa (recordemos, casi un $30 \%$ de temporalidad en el empleo público de España).

A través de su Preámbulo, tanto el Real Decreto-ley 14/2021, de 6 de julio, de medidas urgentes para la reducción de la temporalidad en el empleo público como la posterior Ley, reconocen en varias 
ocasiones la inadecuada utilización de la figura del personal funcionario interino y el abuso de la temporalidad ${ }^{17}$.

Así las cosas, el Real Decreto-ley 14/2021 (y por extensión la Ley derivada) muestra en su motivación inicial una firmeza infrecuente en el bloque jurídico administrativo (al menos en el ámbito organizativo) con la finalidad de corregir los excesos cometidos con el recurso a la temporalidad y, también, puede suponerse de manera razonable, evitar cálculos u opciones de oportunidad, dejando muy claro que pese a los procesos de estabilización que la propia norma contempla, éstos no volverán a repetirse.

En todo caso, el Preámbulo del Real Decreto-ley no puede ser más claro y exigente respecto a sus pretensiones ${ }^{18}$ :

- Reforzar el carácter temporal de la figura del personal interino.

- Aclarar los procedimientos de acceso a la condición de personal interino.

- Objetivar las causas de cese de este personal.

- Declarar la nulidad radical de todo acto, pacto, acuerdo o disposición reglamentaria, así como sus actos de ejecución o desarrollo, cuyo contenido suponga el incumplimiento de los plazos máximos de permanencia del personal temporal.

- Implantar un régimen de responsabilidades que constituya un mecanismo proporcionado, eficaz y disuasorio de futuros incumplimientos.

Por supuesto, el endurecimiento normativo y las mayores exigencias en orden a reglar de manera más exacta y limitada el empleo de la temporalidad dentro de los parámetros de urgencias y necesidad, impidiendo desnaturalizar, especialmente, la figura de la interinidad, suponen en todo caso un acierto ${ }^{19}$.

El establecimiento de un régimen de responsabilidades como rompiente a la impunidad o, desde otra perspectiva, desmontar la facilidad para tomar decisiones claramente desacertadas por su alejamiento de las más elemental planificación o gestión de personal, supone un revulsivo en el ejercicio de la potestad organizatoria como un «mecanismo proporcionado, eficaz y disuasorio para el cumplimiento del deber de evitar abusos en la temporalidad del personal al servicio de las Administraciones Públicas».

Exigencia de responsabilidad expresada en la incorporación al Estatuto Básico del Empleado Público de una nueva disposición adicional decimoséptima, en la que se prevé un régimen de responsabilidades en caso de incumplimiento. Norma que si bien se ha redactado en términos de absoluta generalidad, sin establecer en qué se concreta la posible responsabilidad y cuáles habrán de ser las actuaciones que permitan asegurar el cumplimiento de las previsiones normativas al objeto de evitar irregularidades en la contratación laboral de personal y el nombramiento de personal funcionario interino, supone un hito normativo de especial significación en la construcción de un marco jurídico que excluya la impunidad del desacierto por incumplimiento.

No obstante, todo lo expuesto, si esta fuera la primera vez que en una materia concreta se apela a la obligación de evitar irregularidades y el establecimiento de un régimen sancionador efectivo, la satisfacción sería absoluta asentada en una confianza sin fisuras. Pero la realidad y sus hechos conducen a la desconfianza haciendo buena la perturbadora afirmación realizada por BIELSA a principios del siglo pasado al considerar el Derecho Administrativo como una rama del Derecho cuya aplicación es incierta, arbitraria e infructuosa (Bielsa, 1923, p. 35).

17 La cita del Proyecto de Ley no deja lugar a dudas: «... se endurecen las previsiones legales en cuanto a la duración máxima del nombramiento del personal interino por vacante, como medida preventiva para evitar un uso abusivo de esta figura para ejercer funciones de carácter permanente o estructural...».

18 Punto III del Preámbulo al Real Decreto-ley 14/2021, de 6 de julio, de medidas urgentes para la reducción de la temporalidad en el empleo público.

19 Esta afirmación tiene sus matices. Por un lado, al tomar conciencia de lo que supone reiterar una vez más, en este campo pero también en otros ámbitos, conceptos y presupuestos materiales evidentes, que en el caso de la temporalidad y su más preclara manifestación, la figura de la interinidad, estaban previstos (para todo el que quisiera entenderlo) desde la Ley de Bases de 1963. Incluso recordando la construcción jurisprudencial del Derecho Administrativo, los fallos judiciales sobre la materia no han podido ser más claros y didácticos. Así, por todas, baste citar la Sentencia del Tribunal Superior de Justicia de Madrid, Sala de lo Contenciosoadministrativo, Sección 7. a de 15 de febrero de 1991 (Ponente: Valeriano Palomino Marín) en cuyo Fundamento Jurídico Cuarto se aclara cualquier duda al respecto: «La interinidad es un fenómeno administrativo provisionalidad que resulta definido normativamente por la concurrencia de dos condiciones: una, la necesidad o urgencia del desempeño del puesto de trabajo por alguien; la otra, que no haya funcionario de carrera que pueda desempeñarlo».

Por otro lado, los matices traen causa en las propias contradicciones en las que incurre el Real Decreto-ley 14/2021 respecto a la caracterización jurídica de la figura del funcionario interino al prever, por ejemplo, compensaciones económicas para quienes no superen el proceso de estabilización. Una nueva muestra del proceso de laboralización del personal funcionario. 
Todo lo expuesto en los anteriores epígrafes hacen que la nueva normativa nazca con la semilla de incertidumbre y la desconfianza. El hecho de que la temporalidad sea, como se sabe, un problema estructural de la Administración Pública, da por sí mismo muestra del escaso aprecio a las directrices normativas en materia de planificación y gestión de personal. Como se ha tratado de evidenciar, no han sido pocas las normas que a lo largo de un ciclo de casi sesenta años (periodo más que suficiente para desarrollar un modelo de empleo público con plena capacidad para responder adaptativamente a la exigencia de prestar unos servicios públicos de calidad) han establecido pautas de organización de personal, caracterizando jurídicamente las principales instituciones y figuras integrantes del modelo de función pública. Sin embargo, el elocuente incumplimiento de estas con una elevado daño al interés general no ha supuesto exigencia alguna de responsabilidad $\mathrm{o}$, al menos, el reconocimiento de alguna culpa o simple negligencia.

No es este, como también se ha apuntado, un problema puntual. La incierta, arbitraria e infructuosa aplicación del Derecho Administrativo que denunciaba BIELSA es general pero puede advertirse que adquiere en el ámbito de la gestión de personal, un aporte de mayor desvalor al integrar, en primer lugar, el rendimiento de un derecho fundamental a acceder a funciones y cargos públicos. Pero, en segundo lugar, un factor de apurada tangibilidad jurídica pero no por ello de menor impacto social y, sobre todo, personal al vincularse a las posibilidades laborales del ciudadano y su sostenimiento económico, la proyección social de su reputación profesional: En definitiva, su realización personal e íntima satisfacción.

El Derecho Administrativo, pese a su carácter técnico-burocrático, contiene y despliega factores de naturaleza intangible, espiritualista podría decirse, que afectan de manera directa a los ciudadanos, a las personas en su ánimo, en su tranquilidad, mucho más en entornos de crisis económica y elevado desempleo. Es en el despliegue de estos factores o efectos, positivos o negativos, donde se identifica buena parte del origen de la confianza o desconfianza pública.

Por ello, pese a que no es posible establecer un orden de importancia o prelación en la vinculación general del proceder de la Administración con la legalidad, resulta admisible reconocer un mayor reproche a los incumplimientos en materia de gestión del personal al servicio de la Administración al afectar un ámbito que se vincula directamente al desarrollo personal del ciudadanos. No es ya que se afecte el espacio de dignidad del ciudadanos, es que las decisiones en materia de personal y la atención que se le otorga, incluida la exigencia de responsabilidad por incumplimiento, se introduce en el ámbito más personal del ciudadano.

Así, en el siglo pasado, lo reconocía MACAREL desde una perspectiva de credibilidad ciudadana en su elementales fundamentos de Derecho Administrativo:

«Nada ofende ni desanima más al ciudadano que los privilegios y personalidades en la distribución de esta especie de favores, y el único medio de no llamar a su lado sino hombres dignos y capaces, es no vender los empleos sino al precio de los talentos y las virtudes» (Macarel, 1843, pp. 395-396).

Consecuentemente, el sistema de acceso al empleo público debe resultar impecable, entendiendo que el uso de técnicas, como las propias del empleo temporal, que limitan el carácter abierto y competitivo de los procedimientos ordinarios de acceso, debe ser absolutamente restrictivo. Cerrando este sistema un régimen de responsabilidad creíble y verdaderamente disuasorio tal cual se ha expresado líneas atrás.

Las inobservancias en la materia, se convierten en verdaderas cargas de profundidad para la legitimidad y credibilidad de las Administraciones Públicas. La confianza y la credibilidad social en sus instituciones se construye a través de la ejemplaridad de decisiones acertadas en un marco de absoluto respeto a la legalidad. Incluso verificando estas circunstancias, a veces, el global descreimiento social en lo público no remonta de inmediato la inercia de desconfianza que históricamente acompaña a la gestión pública. Pero el acierto, al final, se capilariza en la sociedad generando confianza y legitimidad, y en ese sentido la corrección de los incumplimientos rompiendo imágenes de impunidad.

No se descubre nada nuevo si al tratar de identificar las principales causas de la crisis institucional que se padece en España afectando directamente a la solidez de la propia democracia, es posible destacar la negativa percepción ciudadana en materia de planificación y gestión del personal.

En la actualidad, muchas actuaciones en materia de gestión de personal, particularmente las vinculadas a acceso a un empleo público, se sitúan automáticamente bajo la sombra de la sospecha tal es el descreimiento social respeto a la efectiva vigencia y aplicación de los principios de mérito y capacidad. Suspicacia social que resta fortaleza al modelo democrático y de Derecho al hacer que sus servidores, los empleados públicos garantes del sistema, nazcan con el pecado original de la desconfianza o la directa acusación de no haber sido reclutados por su mérito y capacidad para demostrar ser los mejores en el desempeño encomendado. 
Es este un proceso de deslegitimación institucional, en el que, dependiendo de la Administración o entidad que se trate, los niveles de desconfianza y auténtica desacreditación de los seleccionados, resultan inadmisibles para un Estado Democrático y de Derecho de calidad.

\subsection{La exigencia de responsabilidad desde una perspectiva de buena administración}

A la vista de todo lo expuesto es importante la exigencia de responsabilidad, pero no sólo desde una dimensión sancionadora, sino desde un ejercicio de las potestades atribuidas orientadas hacia elementales parámetros de buena administración.

Reorientando el planteamiento, cabría preguntarse si después de 43 años de vigencia constitucional es necesario reiterar la obligada vigencia de los principios de igualdad, mérito y capacidad en materia de personal. O si la evidente inmadurez jurídica y democrática de los órganos superiores de personal exija (y nos parezca correcto, tal y como hemos expresado líneas atrás) el establecimiento de medidas disuasorias al incumplimiento.

Parece que sí, y los hechos así lo atestiguan como, por ejemplo, lo hace muy significativamente el Informe del Tribunal de Cuentas N. ${ }^{\circ} 1384$ de fiscalización del coste para CRTVE de las medidas de gestión de personal adoptadas a consecuencia de la aplicación del Real Decreto-Ley 4/2018 (octubre de 2020) en el que, respecto a la selección de personal directivo de la corporación pública, se realizan dos recomendaciones (cuarta y quinta) que proporcionan una respuesta bochornosa confirmado que no se puede prescindir de la exigencia de responsabilidad ni con dimensión sancionadora, ni, como es el caso, desde un enfoque de compromiso con la buena administración.

Bochorno para cualquiera que tenga una mínimo respeto por lo público tal y como ya hemos expuesto con anterioridad (Nevado-Batalla Moreno, 2021) aun cuando podrá haber quien indique que la exigencia de mérito y capacidad puede llegar a limitas las opciones de quien tiene adquirida la superior legitimidad democrática que le permite nombrar a quien estime más oportuno:

- «Resultaría conveniente que la Entidad definiera la cualificación requerida para el desempeño de cada uno de los puestos de personal directivo, con especial referencia a la formación académica y profesional, a la experiencia y a los méritos específicos que resulten valorables.

- Sería conveniente que la Entidad incorporara expresamente a su proceso de selección de personal directivo principios de buena gestión como los de mérito, capacidad, idoneidad, libre concurrencia y publicidad.».

Sorprende la laxitud con la que el Tribunal de Cuentas solicita a una entidad pública, financiada con recursos procedentes del esfuerzo fiscal de los ciudadanos, que cumpla con pautas elementales en materia de selección de personal aun cuando se trate de puestos de alta dirección.

Lo público no admite, en lo tocante a parámetros de elemental integridad y corrección jurídica (buena administración), la fragmentación o la existencia de espacios más o menos abiertos, más o menos permeables a los postulados, no ya de legalidad ordinaria, sino de directo mandato constitucional.

No pocas construcciones organizativas y pesados desarrollos normativos, no dejan de seguir dando cobertura a una huida del Derecho Administrativo que combinada con no pocos desaciertos, están menoscabando gravemente el crédito y la reputación de todo lo público desterrando de la conciencia social la idea de buena administración.

De qué sirve, por ejemplo, la consagración del principio de personalidad jurídica única de la Administración si después se limita su alcance mediante exquisitas interpretaciones jurídicas que permiten el establecimiento de compartimentos estancos a los principios y valores cuya efectividad otorgan credibilidad y legitimidad a las Administraciones Públicas como son los tantas veces repetidos de igualdad, mérito y capacidad.

Para qué hablar sobre ética pública si en la elección del personal al servicio de los ciudadanos a más alto nivel priman los criterios políticos o de oportunidad sobre los que se asientan en la publicidad, el mérito y la capacidad.

En cargos y funciones públicas de evidente perfil técnico ¿es razonable seguir manteniendo que es la exclusiva voluntad de la autoridad que tiene competencia para acordar su nombramiento la que decide si cumple con las recomendaciones de incorporar «principios de buena gestión como los de mérito, capacidad, idoneidad, libre concurrencia y publicidad»? ¿Se debe seguir entendiendo que este tipo de cargos (directivos) quedan fuera del ámbito de protección del art. 23.2 CE ${ }^{20}$ ? ¿Resulta incompatible alineación o confianza política y capacidad técnica?

\footnotetext{
20 STC 192/2012, de 29 de octubre.
} 
En realidad, el ciudadano medio que no sabe nada de organización administrativa ¿admitiría, si lo supiera, que la provisión de puestos, la selección de personal público se realiza sin considerar el mérito, la idoneidad de los aspirantes y, además, a través de procedimientos opacos?

Ese ciudadano, esa sociedad, que no sabe ni tiene porqué saber nada de organización administrativa, seguro que sí tiene una idea, como poco intuitiva, de lo que es el mérito, la igualdad o la publicidad, y seguro que sabe muy bien del esfuerzo que supone tener y mantener un puesto de trabajo o lo que le costó que su hijo pudiera tener un título académico para permitirle optar a una plaza en la Administración a la que sin embargo no puede acceder debido a las limitaciones que de hecho y de derecho se establecen y toleran.

En este entorno, sirviendo el puntual ejemplo expuesto como síntoma manifiesto de una preocupante patología en la organización pública, se pueden entender mejor muchos de los desaciertos cometidos en materia de gestión de personal, ahora focalizados en el problema de la temporalidad.

\subsection{El escalamiento penal de la responsabilidad en materia de gestión de personal}

Teniendo presente todas las consideraciones y reflexiones expuestas hasta el momento, la impresión que se obtiene se anuda a la idea de incumplimiento. Por ello, como se ha dicho, se aplaude la iniciativa legislativa tendente a responder a los incumplimientos a través de sanciones efectivas, aportando credibilidad a las «nuevas» directrices y normas en materia de temporalidad, además de posibilitar que el Derecho Administrativo y su vertiente sancionadora, cumpla con la función disuasoria que le es consustancial.

No obstante, esta orientación garantista en sede administrativa podría resultar insuficiente. Si durante décadas a penas se ha avanzado en la idea de corrección y cumplimiento, no es irracional pensar que la situación puede seguir manteniéndose.

Es por ello, como cierre a todo lo expuesto, que sin renunciar al papel protagonista del Derecho Administrativo, se abogue por una manifestación más nítida el posible escalamiento de los incumplimientos en materia de gestión de personal hacia la responsabilidad penal.

Poco a poco debe interiorizarse en las autoridades competentes en materia de personal, que la exigencia de responsabilidad por irregularidades en las contrataciones de personal temporal o el nombramiento de interinos puede alcanzar el ámbito penal, de tal forma que la arbitrariedad o el abuso en el empleo de la potestad organizatoria, aun cuando pueda llegar a superar los controles y garantías propios del Derecho Administrativo, tiene en el Derecho Penal, como última ratio, una importante herramienta de restitución y respuesta.

Desde la perspectiva de la planificación y gestión de personal, ámbito de elevada discrecionalidad para el órganos superior de personal, no es sólo atender a los casos de prevaricación que tienen en la selección de personal un paradigmático campo a través de la muy extendida inclinación de crear o proveer plazas pensando en candidatos concretos ${ }^{21}$. Se trata de valorar la discrecionalidad empleando el tamiz formado por los elementos configuradores del tipo penal en el que la arbitrariedad es un elemento medular para definir el reproche penal.

No estaría de más contrastar algunas decisiones y actos en materia de gestión de personal con los perfiles que la doctrina jurisprudencial ha trazado en relación al tipo de la prevaricación.

Entre otras, la Sentencia del Tribunal Supremo, Sala Segunda, de lo Penal, 464/2020 de 21 de septiembre, 2020 (Recurso 1993/2019) realiza un sólido repaso a la doctrina expresada por la Sala en anteriores pronunciamientos, permitiendo sintetizar una serie de fundamentos teóricos y presupuestos materiales que podrían servir para componer ese tamiz penal al que se aludía por el que pasar algunas decisiones organizatorias en materia de personal. A saber:

- El delito de prevaricación administrativa es el negativo del deber que se impone a los poderes públicos de actuar conforme a la Constitución y al ordenamiento jurídico. Por ello el delito de prevaricación constituye la respuesta penal ante los abusos de poder que representan la negación del propio Estado de Derecho. Nada lesiona más la confianza de los ciudadanos en sus instituciones que ver convertidos a sus representantes públicos en los vulneradores de la legalidad de la que ellos deberían ser los primeros custodios.

21 En esos supuestos, resulta clara la mutación de la discrecionalidad organizatoria en arbitrariedad e injusticia, omitiendo, como dice la Sentencia del Tribunal Supremo, Sala Segunda, de lo Penal, 646/2021 de 16 de julio de 2021 (Recurso 3992/2019) la necesidad de dar satisfacción a una demanda de la sociedad, que lógicamente quiere que quien va a estar a su servicio sea el mejor en las funciones que se le reclaman, el de mayor mérito y capacidad de entre los aspirantes. 
- La arbitrariedad, determinante de la prevaricación, aparece en los siguientes supuestos:

- Cuando la resolución, en el aspecto en que se manifiesta su contradicción con el Derecho, no es sostenible mediante ningún método aceptable de interpretación de la ley.

- Cuando falta una fundamentación jurídica razonable distinta de la voluntad de su autor, convertida irrazonablemente en aparente fuente de normatividad.

- Cuando la resolución adoptada -desde el punto de vista objetivo- no resulta cubierta por ninguna interpretación de la ley basada en cánones interpretativos admitidos.

En todos estos casos se pone de manifiesto que la autoridad o funcionario, a través de la resolución que dicta, no actúa bajo el mandato del Derecho orientado al funcionamiento de la Administración Pública conforme a las previsiones constitucionales, sino que hace efectiva su voluntad convertida en fuente de normatividad sin fundamento técnico-jurídico aceptable.

Como mera hipótesis de laboratorio, cabría pensar en muchas de las decisiones que en su día fueron adoptadas en materia de temporalidad y si quien las adoptó sería capaz de superar el contraste legal desde esta perspectiva penal.

Por supuesto estas breves pinceladas no tienen intención de formar un criterio de aplicación definitivo respecto a la prevaricación por el uso impropio de la potestad organizatoria, pero puede suponer un punto de partida en la mirada de las decisiones en materia de gestión de personal que abra el campo de la responsabilidad penal en la tendencia que el Gobierno y el legislador impulsan en orden a atajar los incumplimientos a través de la disuasión sancionadora pero, también, penal.

\section{REFERENCIAS BIBLIOGRÁFICAS}

Beladiez Rojo, M. (2018). Artículo 23.2. El derecho fundamental a acceder en condiciones de igualdad a las funciones públicas. En M. Rodríguez-Piñero, M. E. Bravo Ferrer (dirs.), E. Arnaldo Alcubilla, J. Remón Peñalver (eds.), M. Pérez Manzano y I. Borrajo Iniesta (coords.) Comentarios a la Constitución española (Tomo I, artículos 1 a 65, p. 705). Fundación Wolters Kluwer, Boletín Oficial del Estado, Tribunal Constitucional y Ministerio de Justicia. https://www.boe.es/biblioteca_juridica/publicacion.php?id=PUB-PB-2018-94\&tipo=L\&modo=2

Bielsa, R. (1923). Relaciones de Código Civil con el Derecho Administrativo (p. 35). J. Lajouane \& Cia. Editores.

Boltaina Bosch, X. (2018). Los procesos selectivos «blandos» y sus efectos sobre la profesionalización del empleo público. Revista Vasca de Gestión de Personas y Organizaciones Públicas, 2/2018 (número especial). $140-155$. https://apps.euskadi.eus/z16-a5app2/es/t59auUdaWar/R3/verArticulo?numejem=3\&tipo=S\&seccion=51\&correlativ $\mathrm{o}=1$ \&contenido $=8$ \&locale $=\mathrm{es}$

COMISIÓN PARA EL ESTUDIO Y PREPARACIÓN DEL ESTATUTO BÁSICO DEL EMPLEADO PÚBLICO (2005). Informe de la Comisión para el estudio y preparación del Estatuto Básico del Empleado Público. INAP.

Fernández Ramos, S. (2017). Acceso al empleo público: igualdad e integridad. Revista General de Derecho Administrativo, 46, RI §419189. https://www.iustel.com//v2/revistas/detalle_revista.asp?id_noticia=419189

Fuentetaja Pastor, J. (2020). La utilización abusiva de los funcionarios interinos ante el derecho europeo: entre la transformación en funcionarios de carrera y el derecho a indemnización. Revista de Administración Pública, 212, 201-230. https://doi.org/10.18042/cepc/rap.212.07

García de Enterría, E. (1962). La lucha contra las inmunidades del poder en el Derecho administrativo (poderes discrecionales, poderes de gobierno, poderes normativos). Revista de Administración Pública, 38, 159-161. http:// www.cepc.gob.es/publicaciones/revistas/revistaselectronicas? IDR=1\&IDN=38\&IDA=22227

Jiménez Asensio, R. (23 de mayo de 2021). Calidad de los gobiernos de las Comunidades Autónomas [entrada de blog]. La mirada institucional. https://rafaeljimenezasensio.com/2021/05/23/calidad-de-los-gobiernos-de-lascomunidades-autonomas/

Macarel, M. L. (1843). Elementos de Derecho Público y Político (traducido por F. Enciso Castrillón, pp. 395-396). Librería de los señores Viuda e hijos de Calleja.

Martín Toro, J. (2019). Cuestiones prácticas para el desarrollo de los procesos de estabilización del empleo temporal. El Consultor de los Ayuntamientos, 8 (Sección Zona Local/Rincón local), 127.

Nevado-Batalla Moreno, P. T. (2021). Adopción y control de decisiones públicas: integridad y legitimidad institucional por el acierto (p. 369). Tirant Lo Blanc.

Nieto, A. (2003). Recensión al libro de Mauri Majós, Joan: La selecció dels funcionaris al servei de les entitats locals de Catalunya. Revista de Administración Pública, 161, 565-569. http://www.cepc.gob.es/publicaciones/revistas/revista selectronicas? IDR=1\&IDN=159\&IDA=35886

Rivero Ortega, R. (2020). Responsabilidad personal de autoridades y empleados públicos. El antídoto de la arbitrariedad [Ediciones El Cronista] (pp. 22). Iustel. 